\title{
New Drive Converter and Digital Control for the Pulsed Power Supply System of ASDEX Upgrade
}

\author{
Claus-Peter Käsemann ${ }^{\mathrm{a}}$, Christian Jacob ${ }^{\mathrm{a}}$, Hong Ha Nguyen ${ }^{\mathrm{a}}$, Ferdinand Stobbe ${ }^{\mathrm{a}}$, Alois Mayer ${ }^{\mathrm{a}}$, \\ Edgar Sachs ${ }^{\mathrm{b}}$, Reiner Klein ${ }^{\mathrm{b}}$ and the ASDEX Upgrade Team ${ }^{\mathrm{a}}$ \\ ${ }^{a}$ Max Planck Institute for Plasma Physics, Boltzmannstraße 2, 85748 Garching, Germany \\ ${ }^{b}$ Siemens AG, Industrial Automation Systems, Gleiwitzer Straße 555, 90475 Nürnberg, Germany
}

\begin{abstract}
Safety and reliability are major issues for the ASDEX Upgrade (AUG) pulsed power supply systems. To avoid long downtimes during an experimental campaign, fault-prone components have to be identified and treated early. This becomes even more important due to the AUG participation in the EUROfusion Medium Sized Tokamak (MST) program. Operating equipment which is up to 40 years old adds additional complications. This contribution describes one such example where a 35 year old flywheel generator at AUG was identified as fault-prone and pre-emptively upgraded with a new drive converter with integrated control. Most challenging was to adapt a modern converter, originally designed for wind turbines, towards a drive system for a flywheel-motor-generator system. To identify the layout of the controller and the control parameters, accurate modelling and comprehensive simulations were performed. This effort paid off during commissioning and measuring results verified the calculated design values. Finally, the system shows good performance during AUG plasma experiments.
\end{abstract}

Keywords: ASDEX Upgrade; Flywheel motor generator; Power supply; Drive converter; Indirect converter

\section{Introduction}

The operation of ASDEX Upgrade (AUG) relies on three large flywheel generators (EZ2, EZ3 and EZ4). These generators feed the pulsed power supply system for the magnetic confinement (high current) and additional heating (high voltage) of the plasma with stored energies up to $2750 \mathrm{MJ}$ (Fig. 1). To assure a safe and reliable operation, a sophisticated maintenance program is required. Components with an increased probability to fail have to be identified early by evaluation of measured data and error analysis.

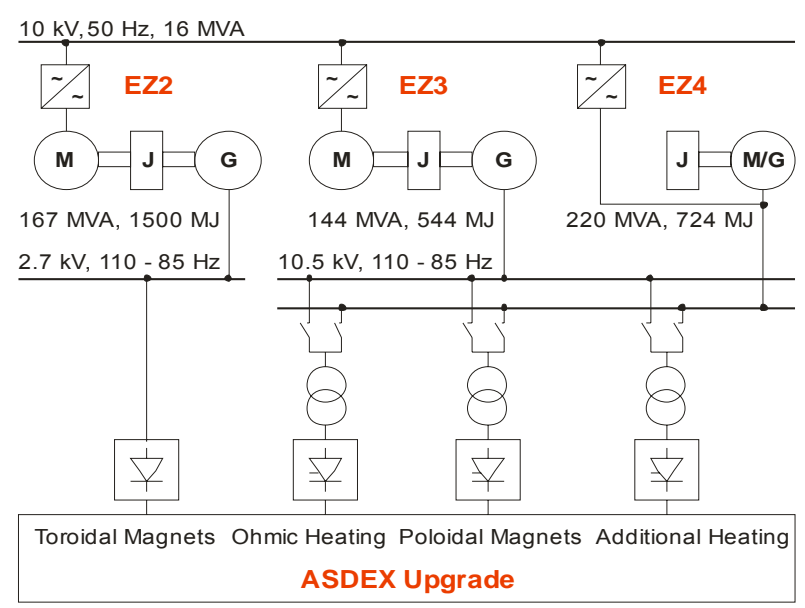

Fig. 1. AUG Pulsed Power Supply Network

One of these critical items was the water-cooled thyristor direct converter for the motor drive of flywheel generator EZ3. During fast load changes, excessive transient asymmetries up to $1000 \mathrm{~A}$ occurred between the three converters feeding the three phases of the rotor.
The result was an increased melting loss of the neutral slip-ring, designed for some $10 \mathrm{~A}$, only. On the other hand, incorrect synchronization of the analog, PCB based control occasionally caused short-circuits and subsequent fuse failures. The reason for both faults was the aging of the power electronics and control components. A lot of time and money had to be spent for repair. The risk of a serious damage to the engine and with that the longer-term shutdown of the generator was always in mind.

All effort to improve the situation did not succeed. Therefore decision was made to substitute the thyristor direct converter and the analog drive control by a new IGBT drive converter with integrated digital control. A first attempt based on an individually designed converter in 2007 exceeded the available budget by far. Five years later, a suitable system used for windmills could be found. This proven technology cut down technical and time risks and reduced costs by $30 \%$. Total project time was 14 month and the EZ3 down time 5 month, only.

\section{Application}

The motor drive of flywheel generator EZ3 is a 7.5 MW doubly-fed four pole induction machine (DFIG) (Fig. 2). The stator is directly connected to the $10 \mathrm{kV} /$ $50 \mathrm{~Hz}$ network. For start-up, the rotor is connected to a hydraulic rheostat (starter resistor). To speed up with almost constant power, the resistance of the rheostat is constantly reduced. At natural frequency $\left(\mathrm{n}_{0} \approx 1495 \mathrm{~min}^{-1}\right.$; rheostat zero) the rotor connection is switched over from the rheostat to the drive converter. The converter is fed from the $10 \mathrm{kV} / 50 \mathrm{~Hz}$ network by a transformer. The output to the rotor is controlled on slip frequency. Changing this frequency in the range 
of -7.5 to $5 \mathrm{~Hz}$, the speed of the flywheel generator can be adjusted between 1275 and $1650 \mathrm{~min}^{-1}$. Three converter modes of operation have to be distinguished: For sub-synchronous operation $\left(\mathrm{n}_{\min }<\mathrm{n}<\mathrm{n}_{0}\right)$ energy is taken from the rotor circuit and fed back to the grid. At synchronous operation $\left(n=n_{0}\right)$ the drive converter generates a stationary field and dc current is fed into the rotor, only. For super-synchronous operation $\left(\mathrm{n}_{0}<\mathrm{n}<\mathrm{n}_{\max }\right)$ the direction of the energy reverses and additional energy is fed into the rotor circuit.

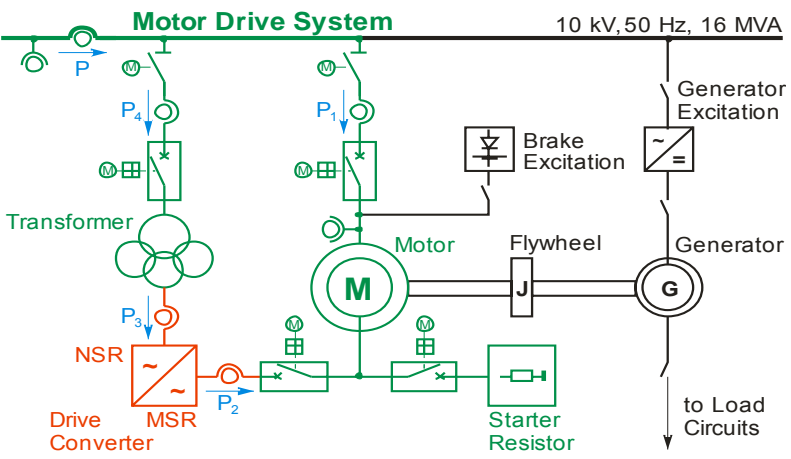

Fig. 2. Doubly-fed Induction Motor Drive EZ3

\section{Converter Concept}

\subsection{Overview}

The new drive converter is based on modern IGBT technology and is already widely used in wind turbines. Feedback control for torque, reactive power and dc link voltage as well as converter protection are integrated in the system. Higher-level control and monitoring, like speed control and overall protection, are implemented into the existing Simatic S7 control. A WinCC display and a mosaic panel are used for operation and visualization. The protection and safety concept of the generator had to be adapted to integrate the new converter.

\subsection{Design Studies and Simulations}

IPP performed detailed calculations and simulations of the control system throughout the whole project. These simulations were necessary to identify required control parameters, to forecast proper behavior of the new drive converter and to prepare required test procedures for commissioning. Based on measurements from the old direct converter, the models were steadily improved according to the latest results of commissioning.

To simulate the start-up process of the generator $\left(\mathrm{n}=0 \quad \ldots \quad \mathrm{n}_{0} \approx 1500 \mathrm{~min}^{-1}\right)$ a simplified Matlab model was used (Fig. 3). Because of the big inertia of the generator assembly $\left(\mathrm{J}_{\text {tot }}=90.4 \mathrm{tm}^{2}\right)$ electrical transients are negligible compared to the mechanical ones. To determine active and reactive power separately, the set of equations of the asynchronous machine was used in a complex $\alpha$ - $\beta$-system. The drive motor is characterized by the parameters $\mathrm{r}_{1}=0.0045, \mathrm{r}_{2}=0.00065, \mathrm{x}_{1 \mathrm{~s}}=0.11$, $\mathrm{x}_{2 \mathrm{~s}}=0.13, \mathrm{x}_{\mathrm{h}}=3.89$ and $\ddot{\mathrm{u}}_{\mathrm{h}}=3.85$. The control of the position of the rheostat to speed up / brake down the system is represented by the rotor-state-resistance $R_{2 Z}$.

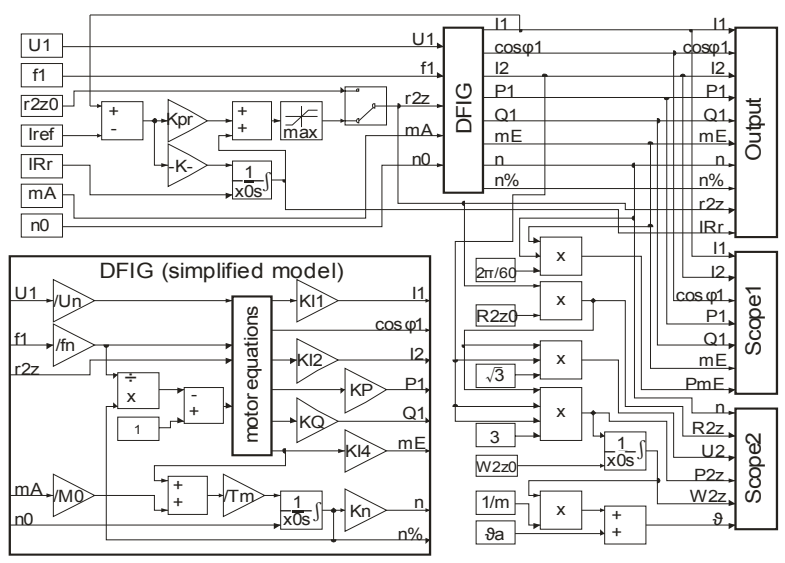

Fig. 3. Matlab Modelling of the Motor Drive

For converter operation an extended model taking electrical transients into account has to be used. The set of equations is (like for synchronous machines) established in the rotor fixed $\mathrm{d}-\mathrm{q}-0$ system [1]. The $\mathrm{d}$-component corresponds to the $\alpha$ - and the q- to the $\beta$-component. The $\alpha-\beta$ - and $d$-q-sets of stator equations are translated into each other by the rotor angel $\vartheta$.

At the indirect drive converter, active power $\mathrm{P}$ and reactive power Q can be controlled separately. Therefore the model provides independent P- and Q-controllers. Descending from wind application, the control parameters for the active power controller are torques. Both controllers provide the amplitude and phase of the three rotor currents $i_{2 L 1}, i_{2 L 2}$ and $i_{2 L 3}$. The frequency $f_{2 u}$ is derived from the rotor angle $\vartheta$. This frequency is not the same as the frequency $f_{2 n}$ derived from the motor speed. Additional rotor phase current controllers of the converter are not implemented into the model. Current reference and actual value are assumed being the same or in other words ac current sources impress the sinusoidal rotor currents. To receive good results, the same control parameters $K_{p}=0.25$ and $T_{n}=20 \mathrm{~ms}$ are used for the active and reactive power controller. For current limiting, two different approaches have been explored. In Fig. 3 a current limiting controller is used. Alternatively the "external reset level hold" function of Matlab integrators can be used, activating the limit via a boolean variable and thus avoiding the controller offset. As an example the results speeding up the generator with maximum rotor current are shown in Fig. 4. The individual limits (see Fig. 6, too) can be distinguished.

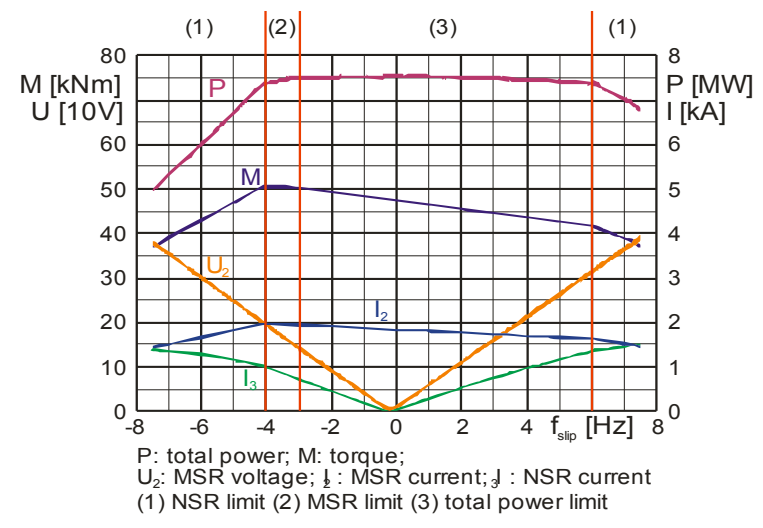

Fig. 4. Simulated converter performance chart 


\subsection{Power Electronics Assembly}

The selected converter Dynavert XL [2] was designed to operate with a doubly-fed asynchronous machine with slip rings used in modern wind generators (Fig. 5). For the EZ3 application, three power units are operated in parallel. Each unit consists of two modules with a net-side inverter (NSR) and a motor-side inverter (MSR) connected via a direct voltage link (dc-link). The converter is equipped with a grid-side filter (reactorcapacitor-resistor arrangement) and a rotor-side filter $(\mathrm{dv} / \mathrm{dt})$. In case of high rotor voltages, the overvoltage protection short-circuits the rotor via a crowbar. For cooling, the semiconductors are mounted on water cooled heat sinks and the cabinets are cooled by airwater heat exchangers. The technical data of the converter are given in Table 1.

Table 1. Drive Converter Main Data

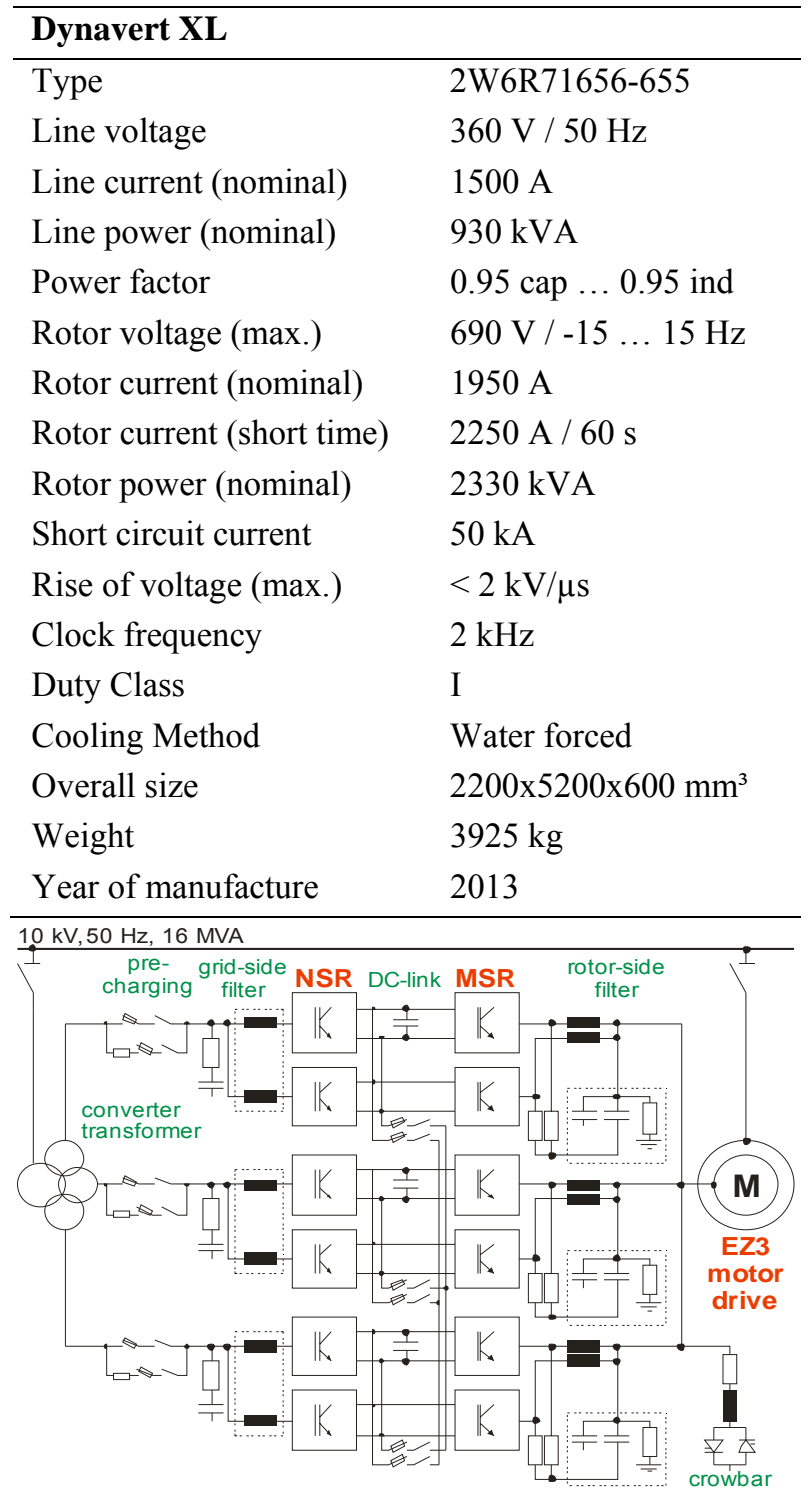

Fig. 5. Single Line Diagram Drive Converter

\subsection{Control and Protection}

The heart of the Dynavert XL is the Loher ControlBoard CB08. The CB08 provides integrated torque, reactive power and intermediate circuit voltage control. In subsidiary control loops the active and reactive current of the NSR and MSR inverters are controlled and finally the PWM signals for the inverters are generated. Accurate synchronization of the motor drive to the grid after rheostatic start-up is performed within the CB08, too. A dual core processor technology is used to provide sufficient performance to optimize the pulse pattern for the converter. This reduces the motor noise and lowers converter and generator losses.

Communication with the superimposed Simatic control is done via Profibus DP. For parameterization and fault finding, there is the possibility of USB or Ethernet communication with the Dynavert software IMS FU-monitor. Alternatively, parameters and error messages can be checked at the local LCD-display.

The superimposed PI speed control is implemented into the existing Simatic control and provides the torque reference $\mathrm{M}_{\text {ref }}$ for the Dynavert XL controller (Fig. 6). In steady state operation $\mathrm{M}_{\text {ref }}$ equals to the torque losses of the generator assembly. To speed up the generator the torque value is increased. The allowed torque is limited by the maximum grid power $\mathrm{P}_{\max }=7.5 \mathrm{MW}$ or by a power limit $\mathrm{P}_{\text {lim }}$ chosen by the operators. Further on, the torque is limited by the current limits of the NSR and MSR inverters (see Fig. 4). To optimize power consumption from the grid, possible inverter braking is suppressed by setting the minimum torque reference to zero $\left(\mathrm{M}_{\min }=0\right)$. The assembly coasts down to lower speed levels, only. By default the reactive power reference is set to zero, too. But up to 1 MVAr additional reactive power could be provided to the grid if desired.

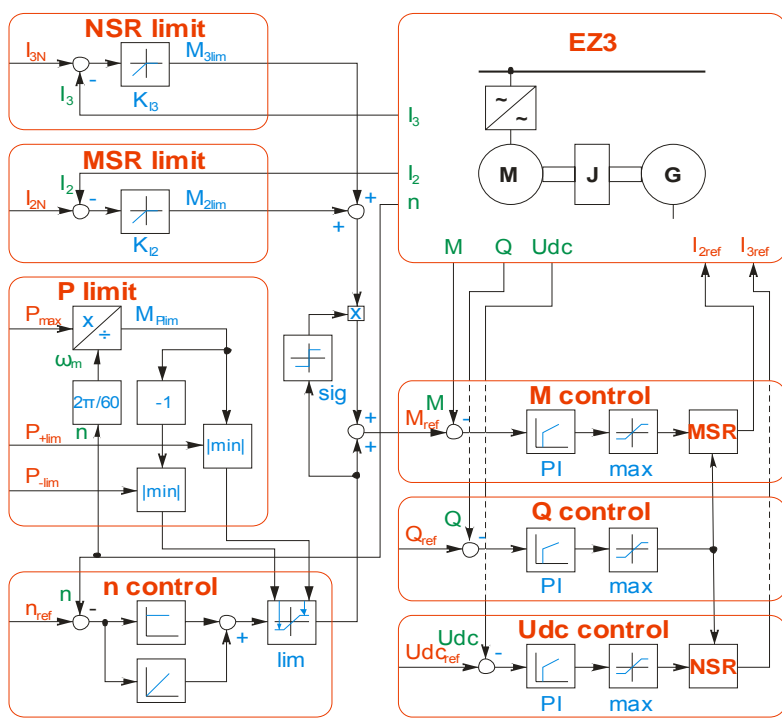

Fig. 6. Speed control and torque limiting

\section{Commissioning}

The main concern during the project was, if the chosen converter will fulfil the required drive parameters for this new application (sufficient power and torque to drive the flywheel assembly with respect to voltage and current limits of the drive motor). The accompanying simulations showed good results. But the Matlab model - programmed some years ago for the IPP DFIGs at the University of Rostock [3] - was based on a direct converter and had to be adapted for an indirect converter by IPP. Therefore attention had to be paid during 
commissioning if the new model and simulation results meet the measurements.

In a first step, six stationary operating points within the speed range $1275 \ldots 1650 \mathrm{~min}^{-1}$ were selected to measure drive power $\mathrm{P}$, stator power $\mathrm{P}_{1}$, MSR power $\mathrm{P}_{2}$, NSR power $\mathrm{P}_{3}$ and transformer primary power $\mathrm{P}_{4}$ (see Fig. 2). With these data indicated in Fig. 7 the friction characteristics $\mathrm{m}_{\mathrm{vR}}=\mathrm{m}_{\mathrm{RN}} *\left(\mathrm{n} / \mathrm{n}_{\mathrm{N}}\right)^{\exp }=5575 \mathrm{Nm} *$ $\left(\mathrm{n} / 1500 \mathrm{~min}^{-1}\right)^{1.865}$ of the generator shaft line could be determined.

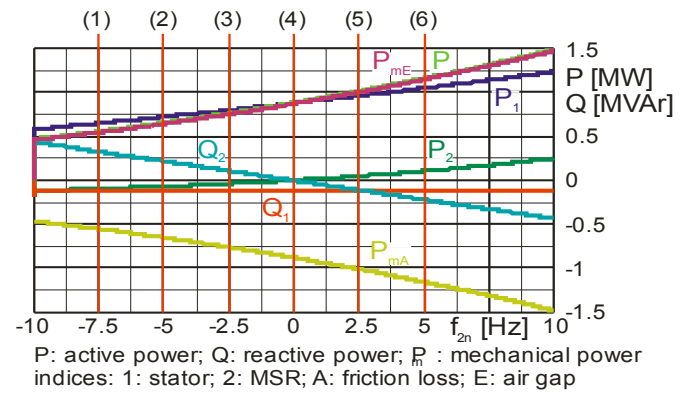

Fig. 7. Stationary drive converter characteristics

To check the dynamic behavior, acceleration tests have been performed. Speed $n$, stator voltage $u_{1}$, active power $p_{1}$, reactive power $\mathrm{q}_{1}$ and current $\mathrm{I}_{1}$ as well as rotor voltage $\mathrm{u}_{2}, \mathrm{U}_{2}$ and current $\mathrm{i}_{2}, \mathrm{I}_{2}$ have been measured. Deviations are within a tolerable range of $5 \%$ (Fig. 8).
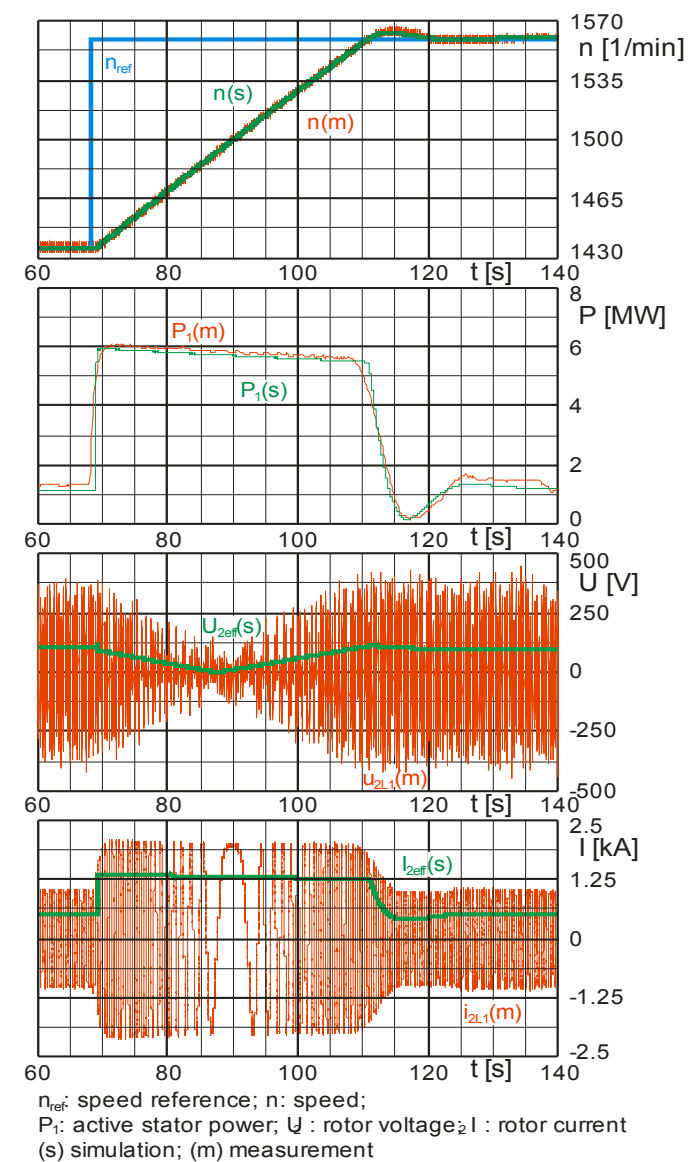

(s) simulation; $(\mathrm{m})$ measurement

Fig. 8. Dynamic behavior of the drive converter

Finally the parameters applied for the Simatic speed control should be verified. Since the Simatic cycling time is not constant, a mean time $\mathrm{T}_{\mathrm{R}}=\left(\mathrm{t}_{\text {End }}-\mathrm{t}_{\text {Begin }}\right) / \mathrm{N}$ $=(391.25107-8.79626) \mathrm{s} / 7569=50.5291 \mathrm{~ms}$ has been calculated and used for simulation. In Fig. 9 the calculated and measured curves show a good agreement. The control parameters are $K_{p}=8$ and $T_{n}=3 \mathrm{~s}$.

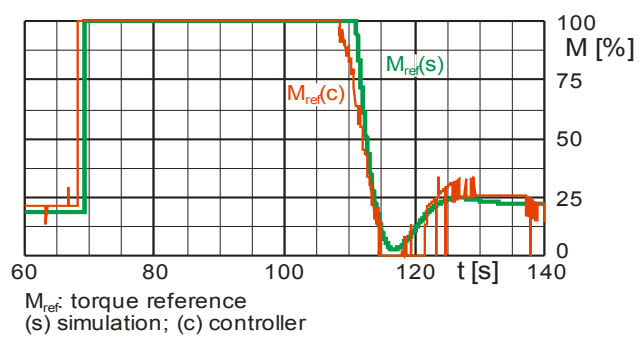

Fig. 9. Verification of speed controller parameters

\section{Operational Experience}

The new drive system is in regular operation since January 2014. Manual operation allows for the required flexibility during commissioning and fault finding. Automatic mode ensures easy operation of the machine set by local staff and by the AUG remote control system. The drive converter fully serves its purpose and no problems or failures occurred so far.

\section{Conclusion}

The decision to adapt a converter system with integrated control already used in industries - instead of a one-off development - allowed replacing the EZ3 motor drive converter within a regular break in AUG operation and available budget. The converter provides the required flexibility to be integrated into a 35 years old installation and into the AUG power supply network. It has sufficient power to drive and speed up the generator-flywheel-assembly over a wide speed range. The control algorithms stably keep the generator at the selected speed level in steady state and dynamically adjust to a new speed without significant overshoot. The active and reactive power management features help to optimize the IPP power demand from the public grid.

\section{Acknowledgement}

This work has been carried out within the framework of the EUROfusion Consortium and has received funding from the European Union's Horizon 2020 research and innovation programme under grant agreement number 633053. The views and opinions expressed herein do not necessarily reflect those of the European Commission.

\section{References}

[1] Hartmut Mrugowsky, Drehstrommaschinen im Inselbetrieb: Modellbildung - Parametrierung Simulation, Springer Vieweg Verlag, 2013, ISBN 978-38348-2136-2

[2] Loher Dynavert Low-voltage wind converter for DFIG, Converter description Dynavert XL, 4BS0659-002, 07/2009

[3] Hartmut Mrugowsky, Untersuchungen und Matlab/Simulink-Modell zum EZ3-Antriebssystem, Abschlussbericht der Universität Rostock, 30.08.2009 